\title{
Hepatitis B virus $X$ protein inhibits apoptosis by modulating endoplasmic reticulum stress response
}

\author{
Jia $\mathrm{Li}^{1,4}$, Jiang $\mathrm{He}^{2,3}$, Yongming $\mathrm{Fu}^{1}$, Xingwang $\mathrm{Hu}^{1}$, Lun-Quan Sun ${ }^{2,3}$, Yan Huang ${ }^{1}$ \\ and Xuegong Fan ${ }^{1}$ \\ ${ }^{1}$ Department of Infectious Diseases, Hunan Key Laboratory of Viral Hepatitis, Xiangya Hospital, Central South University, \\ Changsha 410008, China \\ ${ }^{2}$ Center for Molecular Medicine, Center for Molecular Medicine, Xiangya Hospital, Collaborative Innovation Center for Cancer \\ Medicine, Central South University, Changsha 410078, China \\ ${ }^{3}$ Key Laboratory of Molecular Radiation Oncology, Changsha 410008, China \\ ${ }^{4}$ Department of Emergency, Xiangya Hospital, Central South University, Changsha 410008, China \\ Correspondence to: Xuegong Fan, email: xgfan57@126.com \\ Yan Huang, email: drhyan@163.com \\ Keywords: HBV; HBx; hepatocellular carcinoma; ER stress; apoptosis
}

Received: March 15, $2017 \quad$ Accepted: August 26, $2017 \quad$ Published: October 06, 2017

Copyright: Li et al. This is an open-access article distributed under the terms of the Creative Commons Attribution License 3.0 (CC BY 3.0), which permits unrestricted use, distribution, and reproduction in any medium, provided the original author and source are credited.

\section{ABSTRACT}

Chronic Hepatitis B virus (HBV) infection is a major risk of hepatocellular carcinoma (HCC) worldwide. Hepatitis B virus $X$ protein (HBX) is encoded by one of the four open reading frames of $\mathrm{HBV}$, and is well known as an important coactivator for HBV replication and HBV-associated hepatocellular carcinogenesis. However, its role in keeping cells from apoptosis to promote HCC proliferation remains controversial. Here, we used HBx expressing HCC cells as a model, to investigate the mechanism of HBX-mediated cellular response to endoplasmic reticulum (ER) stress. We found that HBX protein was localized in ER lumen and interacted with GRP78 directly. This interaction resulted in suppression of eIF2a phosphorylation, inhibited expression of ATF4/CHOP/Bcl-2, and reduced cleavage of poly ADP-ribose polymerase (PARP) and level of YH2AX, thus preventing HCC cells from cell death and negatively regulating DNA repair. This study reveals a novel mechanism of the HBX-mediated oncogenesis and provides a basis for potential HBx-targeted therapeutic intervention of HCC.

\section{INTRODUCTION}

Chronic Hepatitis B virus (HBV) infection is closely associated with the development of liver cirrhosis and then progression to hepatocellular carcinoma (HCC) [1]. Although HBV association with HCC has been well documented, the sophisticated mechanisms of HBVmediated oncogenesis remain to be fully elucidated. Among the proteins translated from the open reading frames of HBV genome, HBx protein has been shown to play prominent roles in $\mathrm{HBV}$-mediated carcinogenesis. HBx is mainly localized in the nucleus and mitochondria, and is a multifunctional transactivator that regulates host cell proliferation, metabolism, autophagy and senescence [2-5]. However, how HBx causes hepatocytes transformed or maintains malignancy of HCC remains still elusive.
Liver is the largest exocrine gland and detoxification organ in the human body, and the endoplasmic reticulum (ER) in hepatocytes has a complex functionality. Abnormal accumulation of unfolded proteins that exceed the capacity of the protein folding machinery will lead to a state of "ER stress", which at the early phase stimulates unfolded protein response (UPR) to protect hepatocytes by inhibiting protein synthesis [6]. However, sustained or excessive ER stress induces apoptosis. To counter the HBV-induced ER stress, the virus must have an adaptive mechanism to maintain survival of the infected cells.

During ER stress, there are three major UPR stress sensors including PERK (PKR-like ER kinase), IRE1 $\alpha$ (inositol-requiring enzyme $1 \alpha$ ) and transcription factor ATF6. Under UPR, the diverse substrate repertoire of GRP78 enables it to function as a master regulator of the 
UPR by binding to and inactivating the three ER stress sensors, PERK, IRE1, and ATF6 [7]. During ER stress, increased levels of unfolded protein substrates lead to the sequestration of GRP78, freeing the sensors to initiate UPR signaling. ER stress leads to phosphorylation of PERK and its downstream signal molecule eukaryotic translation initiation factor- $\alpha$ (eIF2 $\alpha$ ), which then causes global translation attenuation, while paradoxically increases ATF4 and C/EBP-homologous protein (CHOP) expression. During prolonged ER stress, $\mathrm{CHOP}$ acts as a death-related transcription factor to promote transcription of the apoptosis associated genes such as Bcl-2, DR-5 and Puma, which lead to cell apoptosis $[8,9]$. In another branch of the UPR signal pathway, activated IRE1 $\alpha$ becomes oligomerized and autophosphorylated, leading to the activation of its cytosolic RNase domain and cleaves the mRNA encoding the transcription factor $\mathrm{X}$ box-binding protein (XBP1). Spliced XBP1 (XBP1s) translocates to the nucleus to induce the expression of its target genes, which participate in ERassociated degradation (ERAD) in order to alleviate ER load. Activated IRE1 $\alpha$ also mediates the rapid degradation of a specific subset of mRNAs encoding plasma membrane and other secreted proteins in a XBP1 independent way to relieve acute ER stress [10]. When ER stress passes a critical threshold, IRE1 $\alpha$ expands its RNase substrate repertoire to many other ER-localized mRNAs, driving cells into apoptosis [11]. The third classical pathway of UPR is mediated by ATF6. Under ER stress conditions, ATF6 is translocated into Golgi apparatus, where it is processed by site- 1 and site- 2 proteases to release a cytosolic fragment (ATF6f) and directly controls the upregulation of genes encoding ERAD components and XBP1 [12].

Many virus infections like Hepatitis C Virus, Herpes Simplex Virus, African Swine Fever Virus and cytomegalovirus, are already known to impose ER stress on the host cells [13-16]. They induce the UPR due to their demand on viral protein production, replication and cell survival. As to $\mathrm{HBV}$ infection, accumulated pre-S proteins and surface antigens in ER lumen have been identified as the cause of hepatocyte UPR [17]. Cellular localization of the viral proteins has been suggested to be one of the determinants for their functions. It has been reported that the large $\mathrm{HBV}$ surface antigens (HBsAg) with deletions at the pre-S1 and pre-S2 regions could be retained in endoplasmic reticulum and resulted in a strong ER-stress response to induce oxidative DNA damage and genomic instability in hepatocytes [18]. HBsAg of the HBV genotype $\mathrm{G}$ with filamentous morphology could also accumulate in endoplasmic reticulum and diminished activation of $\mathrm{Nrf} 2$, thus resulting in defects of liver regeneration [19]. Cho et al reported that HBx could induce the proliferation of hepatocellular carcinoma cells via AP1 over-expression as a result of ER stress [20]. However, the detailed mechanism whereby the HBV infected cells survive from the ER stress caused by HBV infection is still not fully understood.
In this study, we sought to investigate the impact of HBx on ER stress. We assessed the HBx cellular localization, effect of HBx on three UPR sensors, and explored potential mechanism whereby $\mathrm{HBx}$ relieves ER stress to promote HCC survival.

\section{RESULTS}

\section{HBx is localized in ER}

In $\mathrm{HCC}$, the cancer cells need to overcome the chronic ER stress to sustain the pro-survival signals, in which HBx, as one of the key oncogenic proteins, may play a role. To test this hypothesis, we first examined whether HBx could be localized in endoplasmic reticulum. We co-transfected an HBx-GFP plasmid which expressed a green fluorescence $\mathrm{HBx}-\mathrm{GFP}$ fusion protein, and an ER localization signal vector expressing red fluorescence (pDsRed2-ER Vector), to see if these two colors could be merged together. As shown in Figure 1A, the green fluorescence co-located with the red fluorescence. To further confirm this observation, we utilized a flag-HBx vector to co-transfect HepG2 cells with pDsRed2-ER vector and showed that, the flag and DsRed signals were co-localized in ER (Figure 1B). These data suggested that $\mathrm{HBx}$ protein was localized in the ER of HCC cells.

\section{HBx relieves ER stress by binding to GRP78}

To examine the significance of HBx localization in ER, we next investigated if the HBx localized in ER could directly interact with GRP78 by co-immunoprecipitation assays in HepG2 stably expressing $\mathrm{HBx}$ protein. As shown in Figure 2A, HBx could be co-precipitated with GRP78. To further verify the interaction between HBx and Grp78, a Duolink proximity ligation assay was performed to help us visualize $\mathrm{HBx}$ and Grp78 interaction in cells. The results showed that the interaction between $\mathrm{HBx}$ and Grp78 indeed occurred in a time-dependent manner (Figure 2B).

\section{HBx promotes IRE1 $\alpha$ and ATF6 pathways under ER stress}

Having demonstrated a direct interaction between HBx and GRP78, we next examined the effect of this interaction on ER stress responses. IRE1 $\alpha$ pathway has been implicated in generation of pro-survival signals while the ATF6 are involved in production of the proteins needed for protein folding, transport and degradation [21]. We utilized a HepG2 cell stably expressing HBx and tested the ER signaling simulated with two ER stress inducers ( $\mathrm{Tg}$ and tunicamycin $\mathrm{Tm}$ ). As shown in Figure $3 \mathrm{~A}$ and $3 \mathrm{~B}$, IRE1 $\alpha$ was significantly increased in the presence of HBx, which companied with an increase of the XBP1s. For ATF6, we found that although HBx had no impact on 
A

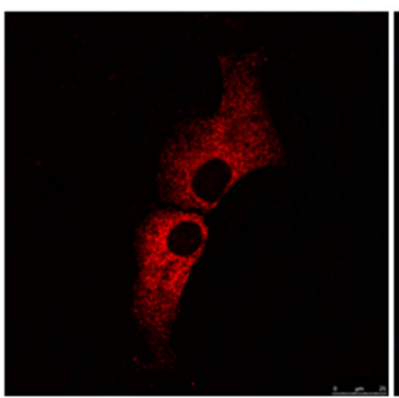

B

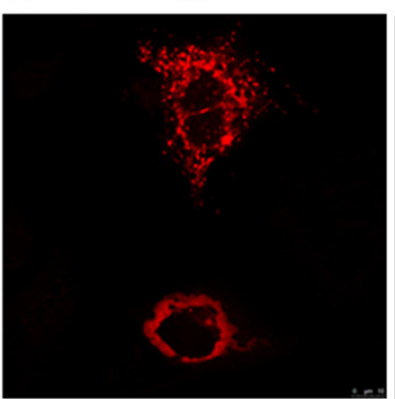

DAPI

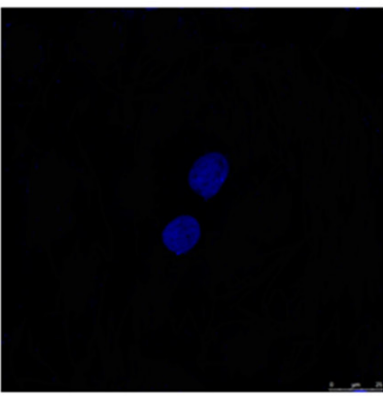

DAPI

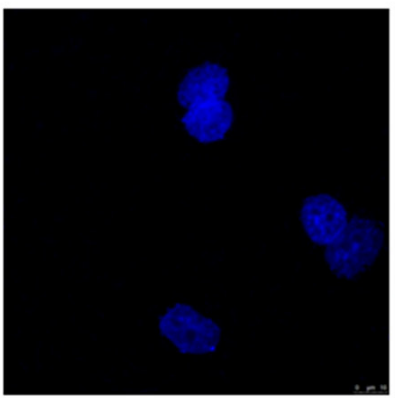

GFP-HBX

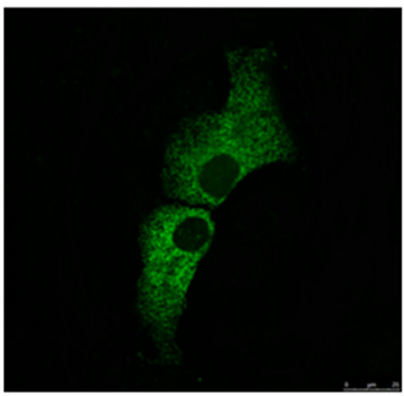

flag-HBX

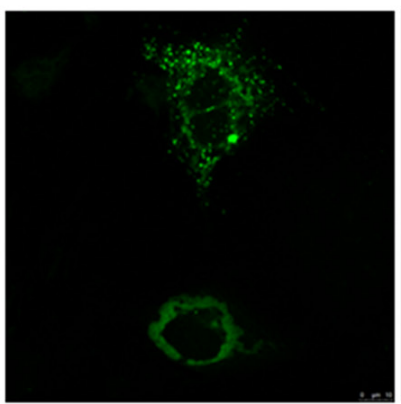

Merged

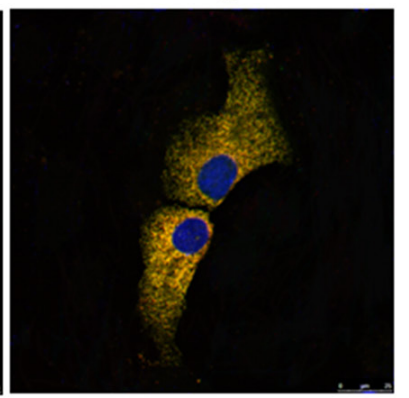

Merged

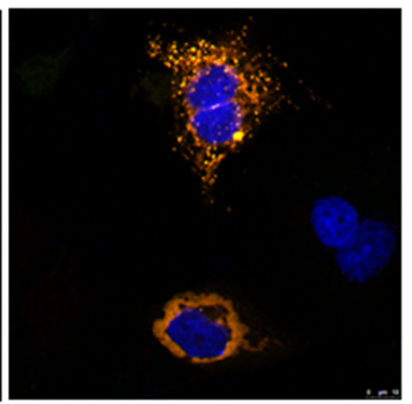

Figure 1: HBx localization on ER. (A) HepG2 cells were co-transfected with pcDNA 3.1-GFP-HBX and pDsRed2-ER plasmids for 24h. Cells were rinsed and fixed. The coverslips were mounted and imaged using a laser scanning confocal microscope. (B) HepG2 cells were co-transfected with pcDNA 3.1-flag-HBX and pDsRed2-ER plasmids for $24 \mathrm{~h}$. Cells were rinsed, fixed, permeabilized and blocked with BlockAid ${ }^{\mathrm{TM}}$ blocking solution. After labeling with anti-flag antibody overnight at $4^{\circ} \mathrm{C}$, cells were washed in PBS and incubated with Alexa Fluor-conjugated secondary antibodies for $45 \mathrm{~min}$ at room temperature. The coverslips were mounted with DABCO anti-fade agent on glass slides and imaged using a laser scanning confocal microscope.

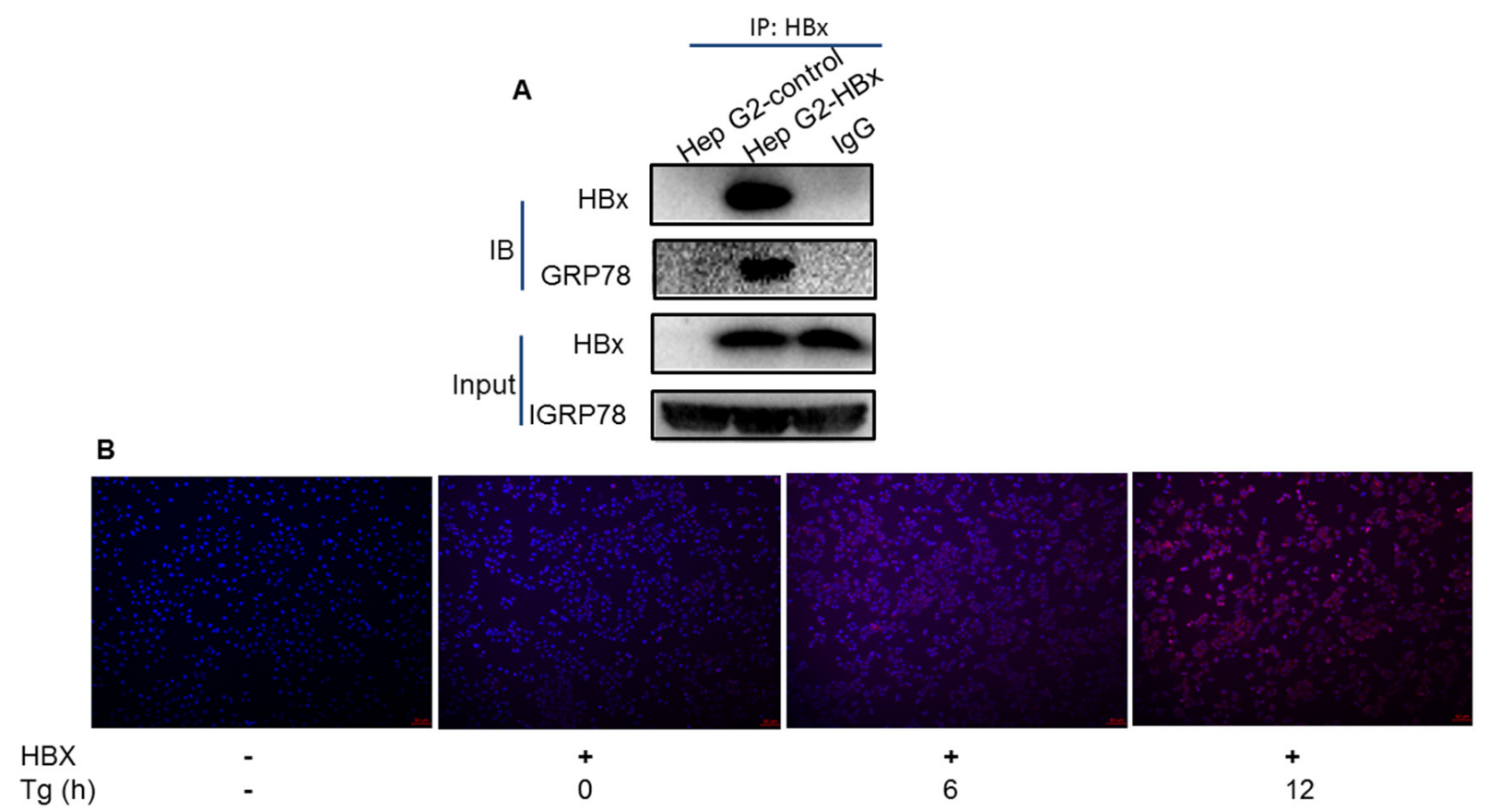

Figure 2: Direct interaction between HBx and Grp78. (A) Protein was extracted from the HepG2 cells expressing HBx or control cells and immune-precipitated with Anti-HBx antibody. The precipitates were subjected to immune-blotting by Anti-HBx and Anti-Grp78 antibodies. Loading control was indicated as Input. (B) Proximity ligation assay in HepG2 cells with or without HBx expression under Tg treatment up to $12 \mathrm{~h}$. The red spots show sites of proximity ligation assay amplification reflecting the interaction between HBx and Grp78. 
the ATF6 mRNA level, expression of HBx actually could promote ATF6 activation at the late time point (Figure 3C and 3D). This data suggested that HBx might impact on IRE1 $\alpha$ and ATF6 branches of ER response to promote cell survival.

\section{HBx modulates ER stress response by inhibiting eIF2 $\alpha / A T F 4$ pathway}

In addition to IRE $1 \alpha$ and ATF6 pathways, we also examined the effect of HBx on PERK signals, which is one of the important branches of UPR. Upon ER stress, PERK dimerizes, autophosphorylating and facilitates the phosphorylation of eIF $2 \alpha$. A phosphorylated eIF $2 \alpha$ proceeds to stop further protein translation, as well as activate the transcription factor ATF4. Under Tg or Tm treatment, the control cells responded well to the ER stress while the $\mathrm{HBx}$-expressing cells showed a significant delay and reduction of eIF2 $\alpha$ and ATF4 expression (Figure $4 \mathrm{~A}-4 \mathrm{C}$ ), indicating that $\mathrm{HBx}$ could inhibit eIF2 $\alpha / \mathrm{ATF} 4$ pathway.

\section{Inhibition of apoptosis by HBx under ER stress}

Following prolonged stress, if not relieved, cell death can be initiated by the UPR. This process is predominantly mediated by ATF4 in the PERK downstream molecules, which enters the nucleus, binds DNA and promotes the gene expression of $\mathrm{CHOP}$ to trigger apoptosis [22]. To verify the effect of HBx on the PERK pathway, we first examined the level of CHOP expression under ER stress conditions in HepG2 cells. The results showed that the CHOP level was significantly reduced in the presence of $\mathrm{HBx}$, compared with the control (Figure $5 \mathrm{~A}$ and $5 \mathrm{~B}$ ). Then the level of $\mathrm{Bcl}-2$, one of the CHOP regulated anti-apoptotic genes, was found to be decreased in $\mathrm{HBx}$-expressing cells (Figure 5E). At cellular level, the HBx-expressing HepG2 cells showed much less proportion of apoptotic cells under $\mathrm{Tg}$ treatment as measured by a TUNEL assay (Figure 5F). Interestingly, when the level of poly (ADP ribose) polymerase 1 (PARP-1), a key executer of DNA repair and apoptosis, was further assayed, we found that the expression of HBx markedly inhibited the level of the cleaved PARP-1 (Figure 5C and 5D), which suggested that HBx inhibited the PERK pathway, avoiding the activation of ATF4-mediated DNA repair. This was further confirmed by measuring level of $\gamma-\mathrm{H} 2 \mathrm{AX}$ (Figure $5 \mathrm{E})$. To exclude the possibility that the observation was cell-specific, we used another HCC cell line Huh7 to verify the results, showing that $\mathrm{HBx}$-expressing Huh7 cells exhibited similar molecular and cellular changes to HepG2 under Tg treatment (Supplementary Figure 1). Together, these data provided evidence of HBx effect on DNA repair and apoptosis.

\section{DISCUSSION}

Human oncoviruses appear to be necessary but not sufficient to cause cancer and are rarely fully oncogenic per se. This indicates that within the context of multistep carcinogenesis, viral infection provides
A

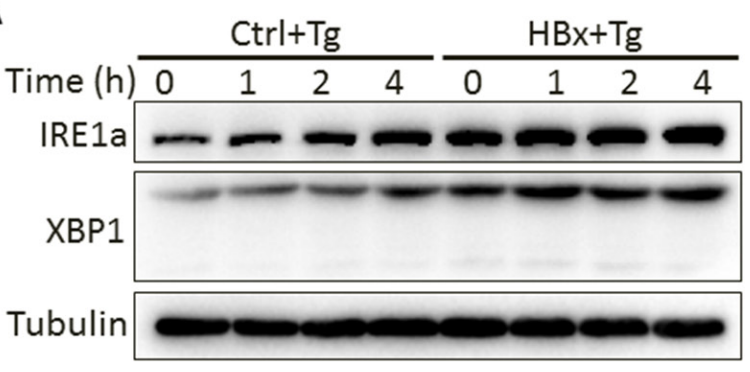

B

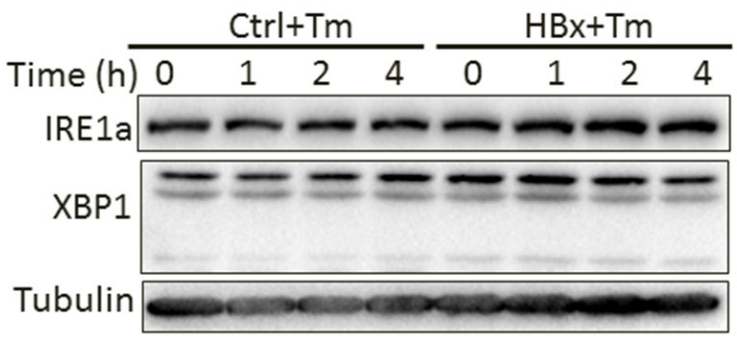

C

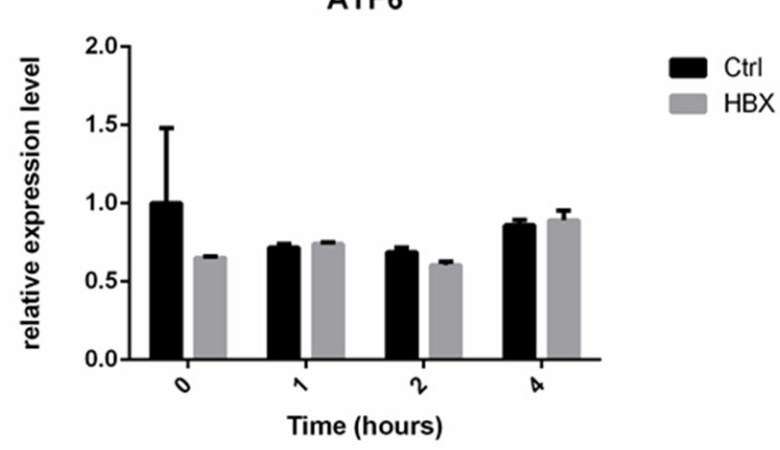

D

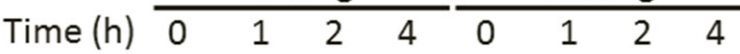

ATF6-90

ATF6-50

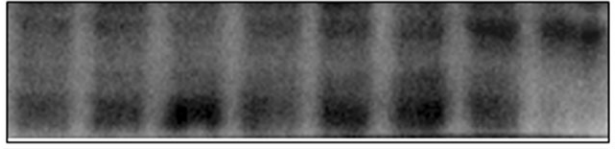

Tubulin

Figure 3: HBx impact on IRE1a and ATF6 pathways. HepG2 cells expressing HBx or control cells were treated for the indicated time with $\operatorname{Tg}(\mathbf{A})$ or $\operatorname{Tm}(\mathbf{B})$. The protein was extracted and subjected to Western blotting (D) and RNA was extracted for RT-PCR of ATF6 expression $(\mathbf{C})$. 
only a subset of the required oncogenic hits [23]. In HCC, HBV establishes chronic infection, and when accompanied by hepatitis, hepatocellular destruction triggers regeneration and fibrosis, which can evolve into cirrhosis and HCC. During the chronic phase of HBV infection, $\mathrm{HBx}$ directly promotes $\mathrm{HCC}$ by altering host gene expression, while immune-mediated inflammation

A
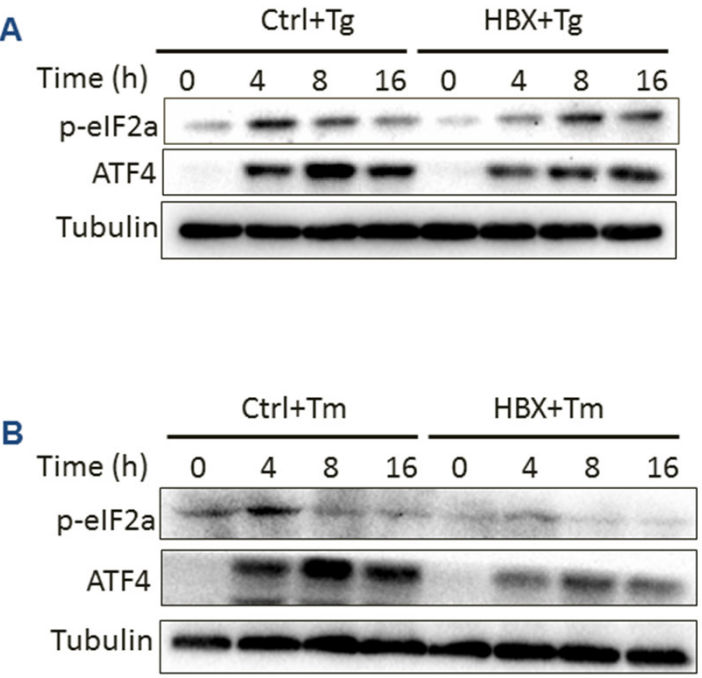

contributes indirectly to tumorigenesis [24]. How HBx alters the host gene expression has been the focus of many intensive investigations. In the present study, we found that HBx could directly interact with Grp78, perturb ER stress response and re-set the host gene expression, which resulted in the acquisition of anti-apoptotic capacity by hepatocytes. This supports the notion that HBV evades

\section{C}

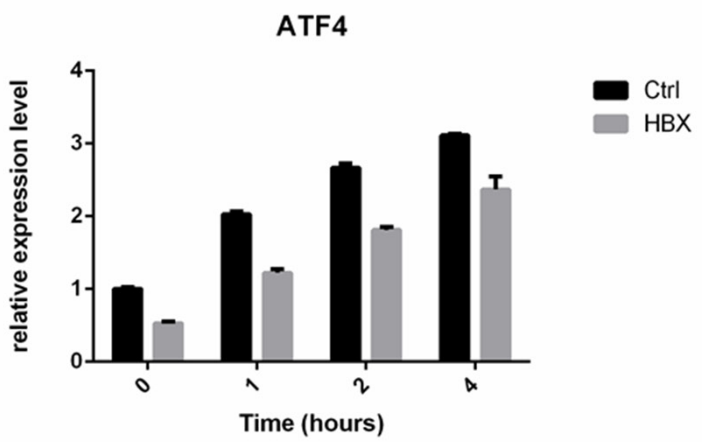

Figure 4: Effect of HBx expression on PERK branch under ER stress condition. (A) HepG2 cells expressing HBx or control cells were treated for the indicated time with $\operatorname{Tg}(\mathrm{A})$ or Tm (B), and p-eIF2a and ATF4 protein levels were measured by Western bots. Relative expression of ATF4 mRNA was detected by RT-PCR assay (C).

A

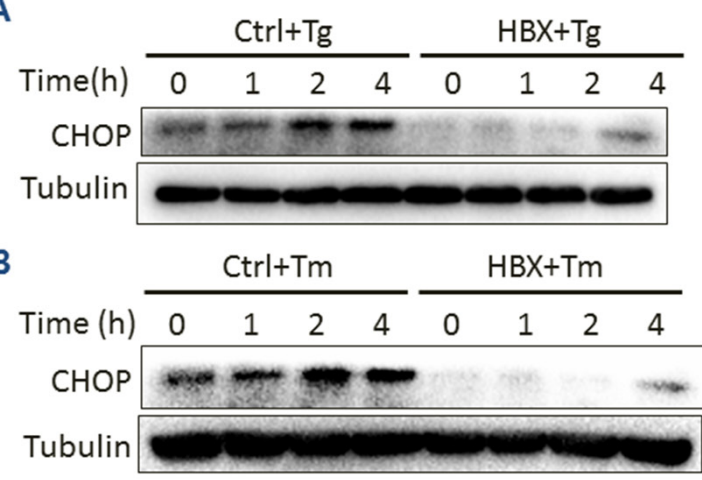

C

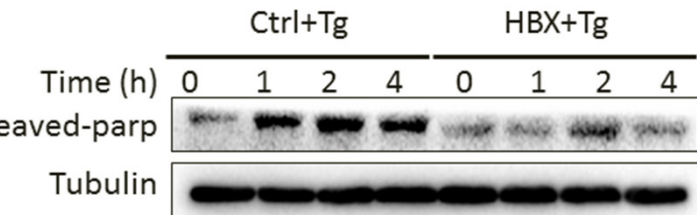

D

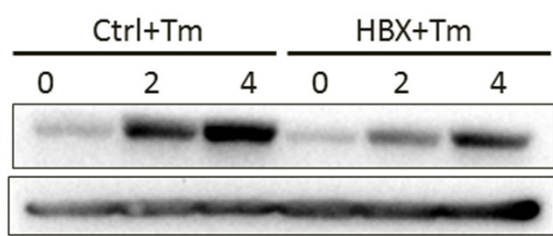

$\mathbf{F}$

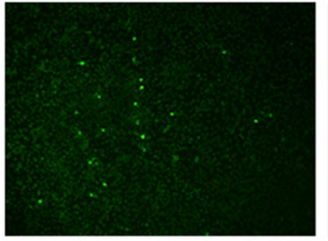

HepG2-control+Tg

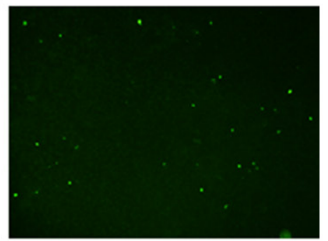

HepG2-HBX+Tg

Figure 5: HBx inhibition of apoptosis and DNA repair. HepG2 cells expressing HBx or control cells were treated for the indicated time with Tg (A, C, E, F) or Tm (B, D). Expression of CHOP (A and B), cleaved PARP (C and D) and $\gamma$-H2AX and Bcl-2 were measure by Western blots. The Tg-treated HepG2 cells were assayed for apoptosis by TUNEL staining $(\mathrm{F})$. 
growth suppression and avoids immune destruction by blocking apoptosis, providing a survival and growth advantage for HBx expressing hepatocytes [25].

IRE $1 \alpha$ is a dual function protein with both kinase and endoribonuclease properties. While the kinase activity is responsible for activating ASK1 and JNK to promote cell death [26], the endoribonuclease activity promotes the splicing of a critical pro-survival gene XBP1 [27]. In this study, we observed that HBx could suppress PERK branch, but activate IRE1a branch although HBx was shown to directly bind to Grp78. We speculate that under the stress condition, HBx binds GRP78, leading to inhibition of PERK branch to avoid apoptosis on the one hand, and activation of IRE1 $\alpha$ branch to further provide the survival advantage on the other hand.

Virus replication presents the host cell with large amounts of exogenous genetic material and unusual structures. The battle between virus and host generates a "genomic conflict". The host attempts to limit viral infection and protect its genome, while the virus deploys tactics to eliminate, evade or exploit aspects of cellular defense, among which the host ER stress responsetriggered DNA repair mechanism appears well-suited machinery used by virus $[28,29]$. In this study, we found that HBx could inhibit PARP-1 that regulates both DNA repair and apoptosis, suggesting that $\mathrm{HBx}$ may function as a mediator to restrict host DNA damage response, thus maintaining survival of the HBV-infected cells.

In conclusion, our study suggests a novel mechanism by which HBV-infected cells escape the ER stressinduced apoptosis via attenuation of PERK activation and restriction of DNA repair response. Thus, direct targeting of HBx in combination with the standard therapy may present a potential strategy for clinical management of HCC.

\section{MATERIALS AND METHODS}

\section{Cell lines, plasmids, transfection and generation of stable cell lines}

HepG2, Huh7 and HEK293T cells were from American Type Culture Collection (ATCC) and maintained at $37^{\circ} \mathrm{C}$ under 5\% CO2 in Dulbecco's modified Eagle's medium (DMEM) added with 10\% fetal bovine serum (FBS), 100U/ml penicillin and streptomycin.

PcDNA 3.1-Flag-HBX, pcDNA 3.1-Flag and pDsRed2-ER plasmids were purchased from Addgene (Cambridge, MA). Transient transfection was performed using X-tremeGENE HP DNA Transfection Reagent (Roche, Shanghai).

Lentiviral transduction system (TaKaRa, Beijing) was used for stable cell line construction. The intact HBX gene was amplified from HepG2 2.15 cells and then inserted into the $\mathrm{pLV}-\mathrm{cDNA}$ vector. The $\mathrm{pLV}$-cDNA containing HBX gene was co-transfected with three helper plasmids (Gag-Pol, Rev and VSV-G) for lenti-cDNA viral stocks generation. After 72 hours transduction of lenticDNA into HepG2 and Huh7 cells respectively, we use BSD for stable cell line selection.

\section{Reagents and antibodies}

Chemical reagents and kits used in this study included Thapsigargin (SIGMA-ALDRICH), Tunicamycin (Beyotime), ApopTag ${ }^{\circledR}$ Fluorescein In Situ Apoptosis Detection Kit (Merck Millipore), and PrimerSTAR ${ }^{\circledR}$ GXL DNA Polymerase (TaKaRa).

Primary antibodies used in this study included the following: Phospho-eIF2 $\alpha$ (Ser51) (CST), ATF4 (CST), CHOP (CST), p58IPK (CST), Cleaved PARP (Asp214) (CST), HSPA5 (Proteintech), HBx (XIAMEN INNOVAX BIOTECH), IRE1a (CST), XBP1 (Abcam). The secondary antibodies used for Western blot were Anti-rabbit IgG, HRP-linked (CTS), Anti-mouse IgG and HRP-linked (CST).

\section{Western blot analysis}

Cells were washed three times with ice-cold PBS and were lysised in RIPA buffer with $10 \%$ cocktail on the ice for $30 \mathrm{~min}$. Lysates were centrifuged at 14000 rpm for $20 \mathrm{~min}$ at $4^{\circ} \mathrm{C}$. Equal amounts of proteins were run on $10-12 \%$ SDS-PAGE gel electrophoresis and then transferred on to PVDF membranes (Millipore). Primary antibodies were incubated in $4^{\circ} \mathrm{C}$ overnight and second antibodies were incubated at room temperature for 1 hour. ECL Western blotting kit was used for protein detecting according to manufacturer's instruction.

\section{Real-time qRT-PCR}

To analyze the expression levels of ATF4 and ATF6 genes, total cellular RNA and subsequent complementary DNAs were prepared. The RNA levels of the genes were quantified by real-time qRT-PCR using the primers were as follows:

ATF4 forward, 5'-TTCTCCAGCGACAAGGCT AAGG-3';

ATF4 reverse, 5'-CTCCAACATCCAATCTGTCC CG-3';

ATF6 forward, 5'- CAGACAGTACCAACGCTT ATGCC-3';

ATF6 reverse, 5'-GCAGAACTCCAGGTGCTTG AAG-3'.

Real-time qPCR was conducted by using an ABI PRISM 7100 Sequence Detection System (Applied Biosystems).

\section{Immuno-precipitation}

Cells were fixed with 4\% PFA for $15 \mathrm{~min}$ and lysed in RIPA buffer. Protein A/G magnetic beads were 
first suspended in binding buffer (50 mM Tris, $150 \mathrm{mM}$ $\mathrm{NaCl}, 0.1 \%-0.5 \%$ Triton 100 or Tween $20, \mathrm{pH} 7.5)$ and then incubated with $5 \mu \mathrm{g}$ Grp 78 or $\mathrm{Hbx}$ antibodies for $1 \mathrm{~h}$ at room temperature with end-over-end rotation. After the supernatant was removed, $200 \mathrm{mg}$ of cell lysate was added to each tube, which was incubated with rotation for $10 \mathrm{~min}$ at room temperature. The immune-precipitated proteins were released by boiling for $5 \mathrm{~min}$ at $95^{\circ} \mathrm{C}$ in dodecyl sulfate sodium salt -Polyacrylamide gel electrophoresis (SDS-PAGE) sample buffer. The magnetic beads were removed with a magnetic separator before the samples were loaded onto a $12 \%$ SDS-PAGE gel.

\section{Immunofluorescence}

Cells were quickly rinsed with pre-warmed PBS and fixed with 4\% paraformaldehyde (PFA) in PBS for $20 \mathrm{~min}$ at $37^{\circ} \mathrm{C}$, permeabilized in $0.5 \%$ Triton $\mathrm{X}-100$ for $20 \mathrm{~min}$ and blocked with BlockAid ${ }^{\mathrm{TM}}$ blocking solution (Thermo Fisher) for $1 \mathrm{~h}$. After labeling with primary antibodies overnight at $4{ }^{\circ} \mathrm{C}$, cells were washed in PBS and incubated with Alexa Fluor-conjugated secondary antibodies for $45 \mathrm{~min}$ at room temperature. All antibody incubations were performed in BlockAid ${ }^{\mathrm{TM}}$ blocking solution. The coverslips were mounted with DABCO anti-fade agent on glass slides and imaged using a laser scanning confocal microscope (TCS Sp8 X\&MP; Leica) equipped with a $63 x / 1.4$ numerical aperture oil-immersion objective (Leica) objective.

\section{Duolink proximity ligation assay}

The in situ proximity ligation assay was performed using a Duolink ${ }^{\circledR}$ In Situ Red Starter Kit for Mouse/Rabbit (DUO92101, Sigma) according to the manufacturer's instructions. Briefly, cells were seeded onto coverslips and circled with a hydrophobic pen the day before the experiment. After treatment, the cells were fixed, permeabilized, blocked, and then incubated with primary antibodies at $4{ }^{\circ} \mathrm{C}$ overnight. After washing, the oligonucleotide (Minus and Plus)-conjugated secondary antibodies were added and incubated for another hour at $37^{\circ} \mathrm{C}$. Subsequently, cells were washed and incubated with ligation solution for $30 \mathrm{~min}$ at $37^{\circ} \mathrm{C}$. The ligated nucleotide circles were amplified using polymerase via the addition of amplification solution and incubation for $100 \mathrm{~min}$ at $37^{\circ} \mathrm{C}$. The slides were washed briefly, and Duolink ${ }^{\circledR}$ In Situ Mounting Medium with DAPI (DUO82040, Sigma) was added to each sample to stain cell nuclei for fluorescence microscopy. The visualized fluorescence spots represented the clusters of protein-protein interactions.

\section{FUNDING}

This work was supported by grant from Special National International Technology Cooperation of
China (2015DFA31490), grant from National Major Sciences research Program of China (973 Program) (No.2013CB910502), grant from National Natural Sciences Foundation of China ( No.81272253) and Natural Sciences Foundation of hunan province (2017JJ3496).

\section{CONFLICTS OF INTEREST}

The authors declare that they have no competing interests.

\section{REFERENCES}

1. Huang JL, Ren TY, Cao SW, Zheng SH, Hu XM, Hu YW, Lin L, Chen J, Zheng L, Wang Q. HBx-related long noncoding RNA DBH-AS1 promotes cell proliferation and survival by activating MAPK signaling in hepatocellular carcinoma. Oncotarget. 2015; 6:33791-33804. https://doi. org/10.18632/oncotarget.5667.

2. Yu Z, Gao YQ, Feng H, Lee YY, Li MS, Tian Y, Go MY, Yu DY, Cheung YS, Lai PB, Yu J, Wong VW, Sung JJ, et al. Cell cycle-related kinase mediates viral-host signaling to promote hepatitis B virus-associated hepatocarcinogenesis. Gut. 2014; 63:1793-1804. https://doi.org/10.1136/ gutjnl-2013-305584.

3. Liu B, Fang M, He Z, Cui D, Jia S, Lin X, Xu X, Zhou T, Liu W. Hepatitis B virus stimulates G6PD expression through HBx-mediated Nrf2 activation. Cell Death Dis. 2015; 6:e1980. https://doi.org/10.1038/cddis.2015.322.

4. Liu B, Fang M, Hu Y, Huang B, Li N, Chang C, Huang R, Xu X, Yang Z, Chen Z, Liu W. Hepatitis B virus X protein inhibits autophagic degradation by impairing lysosomal maturation. Autophagy. 2014; 10:416-430. https://doi. org/10.4161/auto.27286.

5. Zhu R, Mok MT, Kang W, Lau SS, Yip WK, Chen Y, Lai PB, Wong VW, To KF, Sung JJ, Cheng AS, Chan HL. Truncated HBx-dependent silencing of GAS2 promotes hepatocarcinogenesis through deregulation of cell cycle, senescence and p53-mediated apoptosis. J Pathol. 2015; 237:38-49. https://doi.org/10.1002/path.4554.

6. Walter P, Ron D. The unfolded protein response: from stress pathway to homeostatic regulation. Science. 2011; 334:1081-1086.

7. Okada T, Yoshida H, Akazawa R, Negishi M, Mori K. Distinct roles of activating transcription factor 6 (ATF6) and double-stranded RNA-activated protein kinase-like endoplasmic reticulum kinase (PERK) in transcription during the mammalian unfolded protein response. Biochem J. 2002; 366:585-594.

8. Liu K, Shi Y, Guo X, Wang S, Ouyang Y, Hao M, Liu D, Qiao L, Li N, Zheng J, Chen D. CHOP mediates ASPP2induced autophagic apoptosis in hepatoma cells by releasing Beclin-1 from Bcl-2 and inducing nuclear translocation of Bcl-2. Cell Death Dis. 2014; 5:e1323. https://doi. org/10.1038/cddis.2014.276. 
9. Wali JA, Rondas D, McKenzie MD, Zhao Y, Elkerbout L, Fynch S, Gurzov EN, Akira S, Mathieu C, Kay TW, Overbergh L, Strasser A, Thomas HE. The proapoptotic BH3-only proteins Bim and Puma are downstream of endoplasmic reticulum and mitochondrial oxidative stress in pancreatic islets in response to glucotoxicity. Cell Death Dis. 2014; 5:e1124. https://doi.org/10.1038/cddis.2014.88.

10. Hollien J. Decay of endoplasmic reticulum-localized mRNAs during the unfolded protein response. Science. 2006; 313:104-107. https://doi.org/10.1126/ science. 1129631.

11. Ghosh R, Wang L, Wang ES, Perera BG, Igbaria A, Morita S, Prado K, Thamsen M, Caswell D, Macias H, Weiberth KF, Gliedt MJ, Alavi MV, et al. Allosteric inhibition of the IRE1 $\alpha$ RNase preserves cell viability and function during endoplasmic reticulum stress. Cell. 2014; 158:534-548. https://doi.org/10.1016/j.cell.2014.07.002.

12. Lee K, Tirasophon W, Shen X, Michalak M, Prywes R, Okada T, Yoshida H, Mori K, Kaufman RJ. IRE1-mediated unconventional mRNA splicing and S2P-mediated ATF6 cleavage merge to regulate XBP1 in signaling the unfolded protein response. Genes Dev. 2002; 16:452-466.

13. Jiang X, Kanda T, Wu S, Nakamoto S, Wakita T, Shirasawa $\mathrm{H}$, Yokosuka O. Hepatitis C virus nonstructural protein 5A inhibits thapsigargin-induced apoptosis. PLoS One. 2014; 9:e113499. https://doi.org/10.1371/journal.pone.0113499.

14. Cheng G, Feng Z, He B. Herpes simplex virus 1 infection activates the endoplasmic reticulum resident kinase PERK and mediates eIF-2 dephosphorylation by the 134.5 protein. J Virol. 2005; 79:1379-1388. https://doi.org/10.1128/ JVI.79.3.1379-1388.2005.

15. Netherton CL, Parsley JC, Wileman T. African swine fever virus inhibits induction of the stress-induced proapoptotic transcription factor $\mathrm{CHOP} / \mathrm{GADD} 153$. J Virol. 2004; 78:10825-10828. https://doi.org/10.1128/ JVI.78.19.10825-10828.2004.

16. Isler JA, Skalet AH, Alwine JC. Human cytomegalovirus infection activates and regulates the unfolded protein response. J Virol. 2005; 79:6890-6899. https://doi. org/10.1128/JVI.79.11.6890-6899.2005.

17. Su IJ, Wang HC, Wu HC, Huang WY. Ground glass hepatocytes contain pre-S mutants and represent preneoplastic lesions in chronic hepatitis B virus infection. J Gastroenterol Hepatol. 2008; 23:1169-1174. https://doi. org/10.1111/j.1440-1746.2008.05348.x.

18. Hsieh YH, Su IJ, Wang HC, Chang WW, Lei H, Lai MD, Chang WT, Huang W. Pre-S mutant surface antigens in chronic hepatitis B virus infection induce oxidative stress and DNA damage. Carcinogenesis. 2004; 25:2023-2032. https://doi.org/10.1093/carcin/bgh207.

19. Peiffer KH, Akhras S, Himmelsbach K, Hassemer M, Finkernagel M, Carra G, Nuebling M, Chudy M, Niekamp
H, Glebe D, Sarrazin C, Zeuzem S, Hildt E. Intracellular accumulation of subviral HBsAg particles and diminished Nrf2 activation in HBV genotype G expressing cells lead to an increased ROI level. J Heptol. 2015; 62:791-798. https:// doi.org/10.1016/j.jhep.2014.11.028.

20. Cho HK, Cheong KJ, Kim HY, Cheong J. Endoplasmic reticulum stress induced by hepatitis $\mathrm{B}$ virus $\mathrm{X}$ protein enhances cyclo-oxygenase 2 expression via activating transcription factor 4. Biochem J. 2011; 435:431-9. https:// doi.org/10.1042/BJ20102071.

21. DuRose JB, Tam AB, Niwa M. Intrinsic capacities of molecular sensors of the unfolded protein response to sense alternate forms of endoplasmic reticulum stress. Mol Biol Cell. 2006; 17:3095-3107. https://doi.org/10.1091/mbc. E06-01-0055.

22. Marciniak SJ, Yun CY, Oyadomari S, Novoa I, Zhang Y, Jungreis R, Nagata K, Harding HP, Ron D. CHOP induces death by promoting protein synthesis and oxidation in the stressed endoplasmic reticulum. Genes Dev. 2004; 18:30663077. https://doi.org/10.1101/gad.1250704.

23. Bouvard V, Baan R, Straif K, Grosse Y, Secretan B, El Ghissassi F, Benbrahim-Tallaa L, Guha N, Freeman C, Galichet L, Cogliano V; WHO International Agency for Research on Cancer Monograph Working Group (2009). A review of human carcinogens - Part B: biological agents. Lancet Oncol. 2014; 10:321-322.

24. Yip WK, Cheng AS, Zhu R, Lung RW, Tsang DP, Lau SS, Chen Y, Sung JG, Lai PB, Ng EK, Yu J, Wong N, To $\mathrm{KF}$, et al. Carboxyl-terminal truncated HBx regulates a distinct microRNA transcription program in hepatocellular carcinoma development. PLoS One. 2011; 6:e22888.

25. Mesri EA, Feitelson MA, Munger K. Human viral oncogenesis: a cancer hallmarks analysis. Cell Host Microbe. 2014; 15:266-282.

26. Urano F, Wang X, Bertolotti A, Zhang Y, Chung P, Harding HP, Ron D. Coupling of stress in the ER to activation of JNK protein kinases by transmembrane protein kinase IRE1. Science. 2000; 287:664-666.

27. Yoshida H, Matsui T, Yamamoto A, Okada T, Mori K. XBP1 mRNA is induced by ATF6 and spliced by IRE1 in response to ER stress to produce a highly active transcription factor. Cell. 2001; 107:881-891.

28. Han J, Back SH, Hur J, Lin YH, Gildersleeve R, Shan J, Yuan CL, Krokowski D, Wang S, Hatzoglou M, Kilberg MS, Sartor MA, Kaufman RJ. ER-stress-induced transcriptional regulation increases protein synthesis leading to cell death. Nat Cell Biol. 2013; 15:481-490. https://doi. org/10.1038/ncb2738.

29. D'Arcangelo M, Drew Y, Plummer R. The role of PARP in DNA repair and its therapeutic exploitation. In: DNA Repair in Cancer Therapy. Elsevier; 2016, 115-134. https:// doi.org/10.1016/B978-0-12-803582-5.00004-8. 